\title{
Original
}

\section{Advantage of Long Ileus-tube Placement by Gastrostomy for Treating Patients with Refractory Intestinal Obstruction}

\author{
Hiromi Date*, Masahiko Murakami, Makoto Watanabe, \\ Satoru Goto, Kimiyasu Yamazaki, Akira Fujimori, \\ Yuta EnAmi, Koji OtsuKa and Takeshi Aoki*
}

\begin{abstract}
Maintaining a long transnasal ileus tube for a long period can be quite painful for patients such as in those with refractory intestinal obstruction and peritonitis carcinomatosa and it can markedly decrease quality of life (QOL) due to unexpected respiratory complications associated with the tube placement. To mitigate such complications, we undertook a trial insertion of a long ileus tube by gastrostomy in five patients with refractory intestinal obstruction (four cases of peritonitis carcinomatosa and one case of chronic intestinal pseudo-obstruction). We inserted the transgastric ileus tube using a percutaneous gastrostomy catheter kit after puncture with a plastic skin (PS) needle covered with a protective sheath, and then endoscopically placed the tube beyond the ligament of Treitz. Subsequently, we removed the long transnasal ileus tube, and comparable decompression was achieved. In all cases, the entire procedure was easily performed with no complications. Moreover, patients experienced reduced pain and stress and they were able to regain some freedom during activity.
\end{abstract}

Key words : refractory intestinal obstruction, transgastric ileus tube by gastrostomy, peritonitis carcinomatosa

\section{Introduction}

Long-term placement of an ileus tube is necessary in cases such as in patients with peritonitis carcinomatosa and refractory intestinal obstruction. However, inserting such a tube through the nose and maintaining it there over the long term is likely to cause nasal pain and respiratory complications. Moreover, the patient's quality of life (QOL) will become markedly worse. To avoid such outcomes, alternative methods have been reported, such as percutaneous endoscopic gastrostomy (PEG) or percutaneous endoscopic gastrostomy with jejunal extension (PEG-J $)^{1-7)}$. Herein, we report five patients who underwent another new method involving insertion of a long ileus tube by gastrostomy, with good treatment results and increased QOL achieved. This method has been reported previously in only a few published papers.

Department of Surgery, Division of General and Gastroenterological Surgery, Showa University School of Medicine, 15-8 Hatanodai, Shinagawa-ku, Tokyo 142-8666, Japan.

* To whom corresponding should be addressed. 
Table 1. Case List

\begin{tabular}{|c|c|c|c|c|c|c|c|c|}
\hline Case & Age & Gender & $\begin{array}{c}\text { Underlying } \\
\text { disease }\end{array}$ & $\begin{array}{l}\text { Transnasal } \\
\text { ileus tube } \\
\text { Duration of } \\
\text { placement } \\
\text { (days) }\end{array}$ & $\begin{array}{l}\text { Duration of surgery } \\
\qquad(\mathrm{min}) \\
\text { Time required } \\
\text { for placement of } \\
\text { transgastric ileus } \\
\text { tube via gastrostomy }\end{array}$ & $\begin{array}{l}\text { Duration of } \\
\text { transgastric } \\
\text { ileus tube via } \\
\text { gastrostomy } \\
\text { placement } \\
\text { (days) }\end{array}$ & $\begin{array}{l}\text { Possibility } \\
\text { of transition } \\
\text { to home } \\
\text { care and } \\
\text { duration } \\
\text { (days) }\end{array}$ & $\begin{array}{c}\text { Turning } \\
\text { point }\end{array}$ \\
\hline 1 & 80 & Female & $\begin{array}{c}\text { Peritonitis } \\
\text { carcinomatosa } \\
\text { (bladder } \\
\text { cancer) }\end{array}$ & 12 & 23 & Unknown & $\begin{array}{c}\text { Possible } \\
\text { (unknown) }\end{array}$ & Discharge \\
\hline 2 & 68 & Male & $\begin{array}{c}\text { Peritonitis } \\
\text { carcinomatosa } \\
\text { (rectal cancer) }\end{array}$ & 14 & 35 & 910 & Not possible & Discharge \\
\hline 3 & 78 & Male & $\begin{array}{c}\text { Peritonitis } \\
\text { carcinomatosa } \\
\text { (prostate } \\
\text { cancer) }\end{array}$ & 12 & 25 & 17 & Not possible & Death \\
\hline 4 & 46 & Female & $\begin{array}{c}\text { Chronic } \\
\text { intestinal } \\
\text { pseudo- } \\
\text { obstruction }\end{array}$ & 28 & 30 & 553 & $\begin{array}{c}\text { Possible } 471 \\
\text { days }\end{array}$ & Discharge \\
\hline 5 & 69 & Male & $\begin{array}{c}\text { Peritonitis } \\
\text { carcinomatosa } \\
\text { (rectal cancer) }\end{array}$ & 8 & 40 & 45 & Not possible & Discharge \\
\hline
\end{tabular}

\section{Patients and methods}

\section{Patients}

Table 1 details the five cases, comprising two male and three female patients with a mean age of 69 years (range, 46-80 years) in this study. There were four cases of intestinal obstruction due to peritonitis carcinomatosa and one case of chronic intestinal pseudo-obstruction. All patients and their families consented to the gastrostomy procedure for insertion and placement of the long ileus tube.

\section{Surgical procedure}

First, the gastric and abdominal walls were percutaneously fixed using a Funada-style loop gastropexy device under endoscopic guidance (Fig. 1). Then, a plastic skin (PS) needle (16 F) covered with a protective sheath $(166 \mathrm{~mm}$ in length) was guided into the stomach using a percutaneous gastrostomy catheter kit (Create Medic Co., Ltd., Yokohama, Japan) through a planned fistula site (Fig. 2). The PS needle was removed, leaving a peel-away sheath, and a 16-F ileus tube (Create Medic Co., Ltd.) was inserted through this sheath. After insertion, the sheath was 

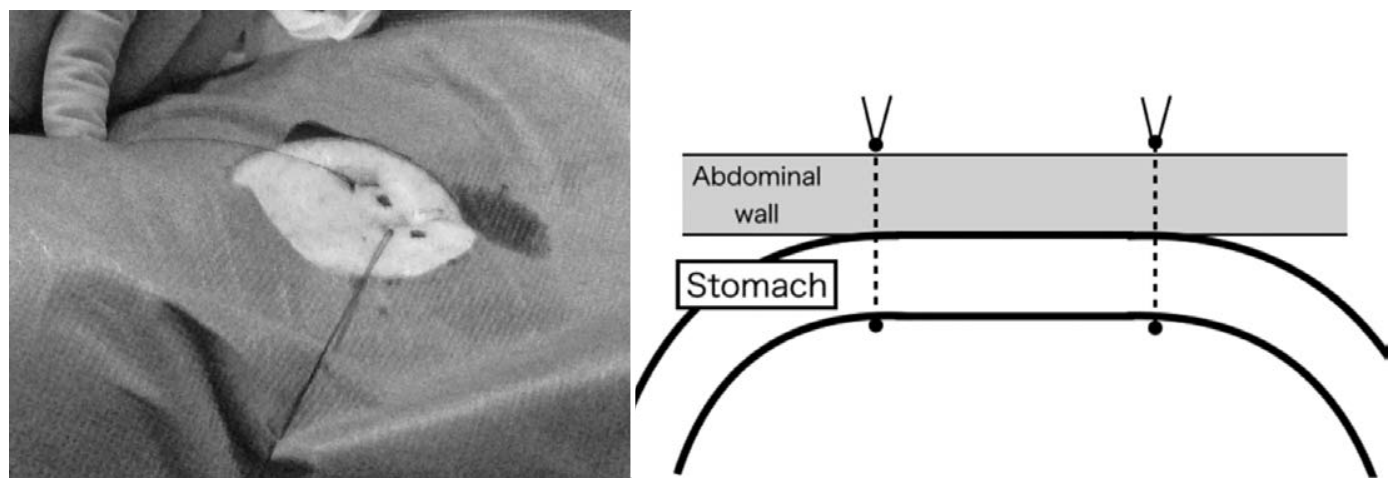

Fig. 1. Fixation of the abdominal wall and stomach using a Funada-style loop gastropexy device and scheme of the fixation.
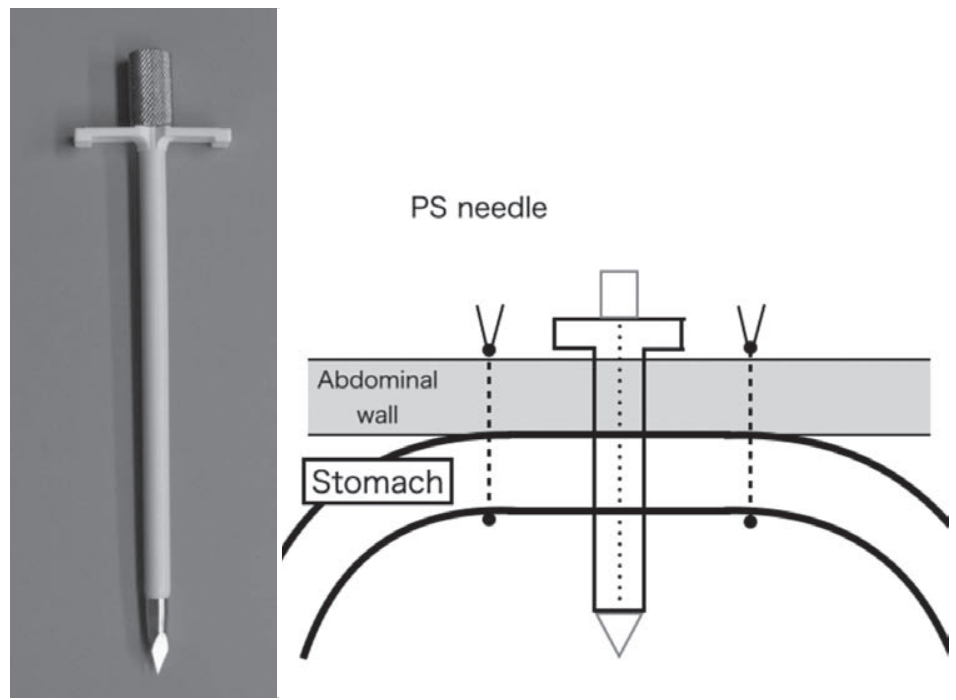

Fig. 2. A vertical puncture was performed with a peel-away, sheath-covered PS needle (Create Medic Co., Ltd.) at the planned fistula site. Scheme shows the puncture procedure.

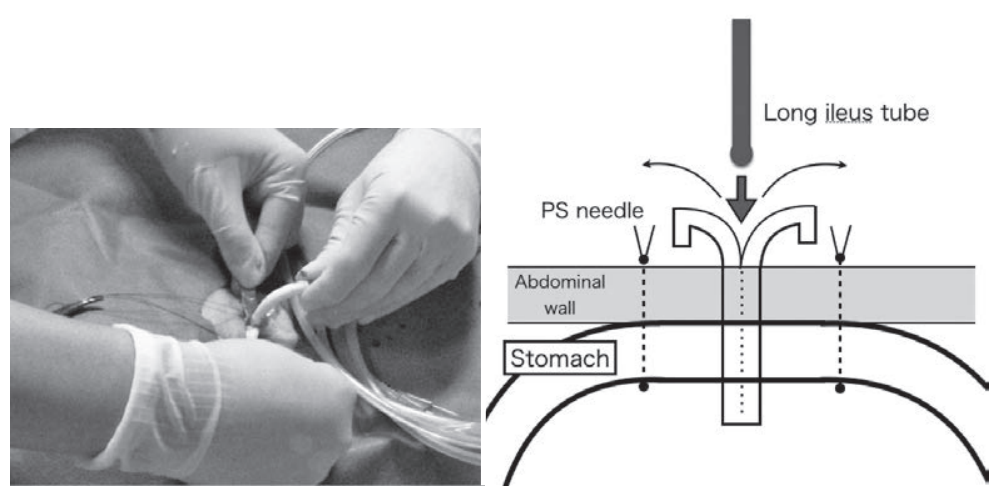

Fig. 3. An ileus tube (Create Medic Co., Ltd.) was inserted as the sheath was being peeled away. Relevant schema show the procedure. 


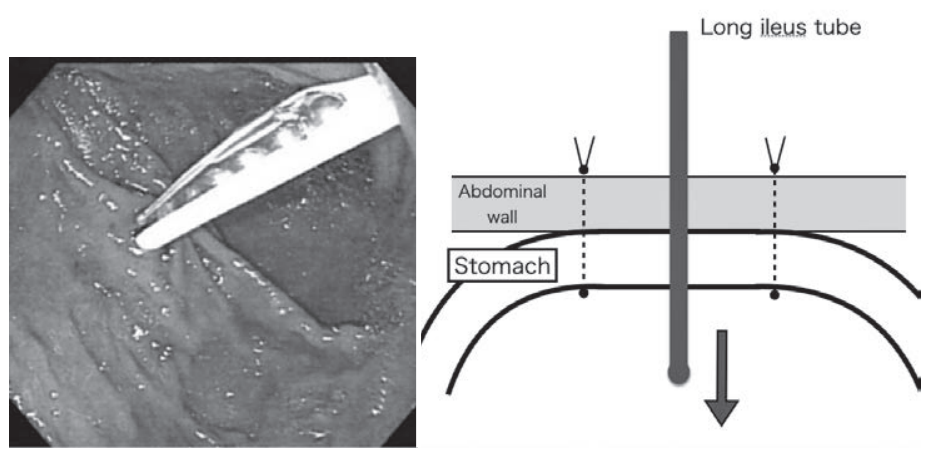

Fig. 4. Intraoperative endoscopic image and relevant schema of the ileus tube tip being inserted into the sheath.

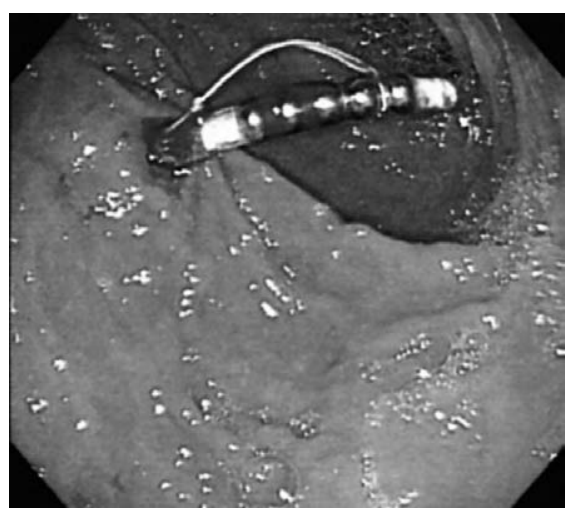

Fig. 5. Intraoperative endoscopic image of ileus tube insertion into the stomach. The tip was secured with a thread to guide it toward the duodenum.

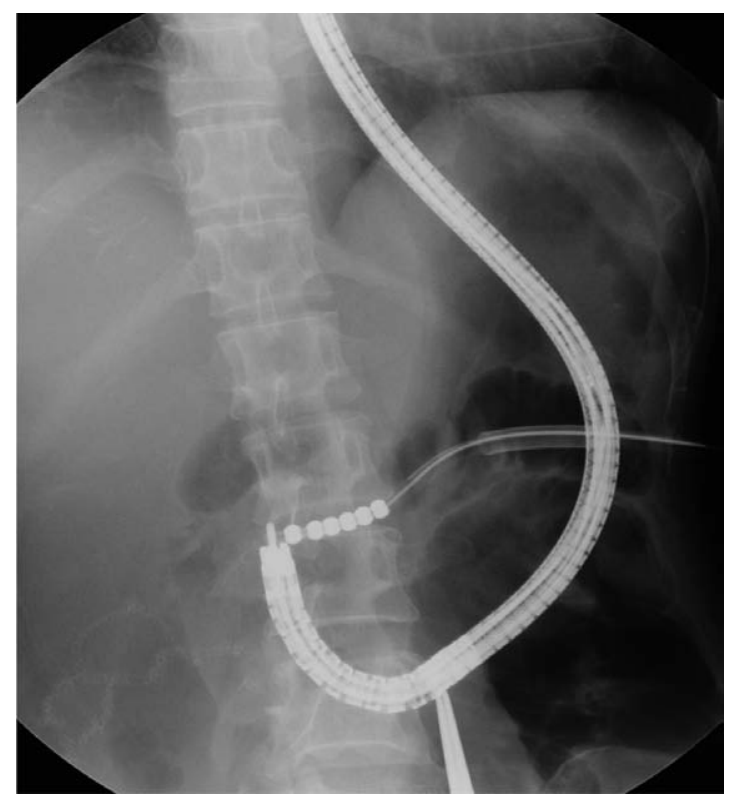

Fig. 6. Intraoperative perspective image. The ileus tube was guided towards the duodenum by gripping the thread secured to the tip of the tube with endoscopic alligator jawstype biopsy forceps.

peeled away (Figs. 3-5). Finally, an ileus tube was endoscopically guided beyond the ligament of Treitz, and fixed to the abdominal wall after proceeding as far to the anus side as possible (Fig. 6). Notably, guiding this ileus tube was much easier than experienced using the nasal approach. 


\section{Results}

The mean duration of inserted transnasal ileus tube was 12 (8-28) days before changing to an ileus tube by gastrostomy. The mean duration necessary for this insertion method was 30 (range, 23-40) min. No patient experienced complications associated with this procedure, such as surgical site infection, and four patients returned home immediately after the procedure. Patient details are presented in Table 1. One patient with chronic intestinal pseudo-obstruction (case 4) could have their ileus tube removed after 471 days. QOL was improved for all treated patients, with specific improvements in neck discomfort and disappearance of nasal pain. It was also possible for the patients to orally ingest some food such as jelly or a liquid diet.

\section{Discussion}

For cases of refractory intestinal obstruction such as peritonitis carcinomatosa or chronic intestinal pseudo-obstruction, gastric and ileus tubes are generally inserted transnasally. However, prolonged placement can cause complications including nasal inflammation and ulceration because of contact pressure applied to the mucosal membranes of the nose, gastrointestinal bleeding, and aspiration pneumonia and sinusitis due to a decline in laryngeal and swallowing functions. These physical complications together with the mental stress caused by long-term placement negatively impact the patient's QOL. Finally, according to Silk et $a l^{1)}, 78.8 \%$ of patients with a nasal gastric tube fitted are plagued by neck discomfort.

To address these complications and the decreased QOL associated with the long-term placement of a transnasal ileus tube, various methods such as PEG and PEG-J have been attempted as alternatives to the nasal approach ${ }^{2-8}$. PEG is an endoscopic technique developed by Gauderer $e t a l^{9)}$ that is now widely used because it is simpler and less invasive than laparotomy. Several reports have described the effectiveness of this method in improving nutrition and the transition to home care, and in reducing medical costs for patients with oral feeding difficulties $^{10,11)}$. Under the present management approaches, PEG will be most indicated for improving nutritional management; however, this approach is not effective for decompressing intestinal fluids in cases of refractory intestinal obstruction ${ }^{2-6)}$.

To address these challenges, we evaluated a newly developed method similar to PEG-J ${ }^{12)}$, which is reportedly as effective as PEG with regard to gastrointestinal decompression ${ }^{7,8)}$. In a study cohort of five patients with refractory intestinal obstruction, we inserted a long ileus tube beyond the ligament of Treitz by gastrostomy. After the procedure, all patients experienced no neck discomfort, improved sleep, and freedom in their daily activities. Patient QOL was also markedly improved, and the patients could ingest water or an oral liquid diet during care at home. This new procedure for inserting the ileus tube seemed to reduce the intestinal pressure associated with nasal placement.

Of note, the few other reports of gastrointestinal decompression when fitting an ileus tube by gastrostomy reported some complications with the tube insertion ${ }^{13-15)}$.

Due to the low incidence of complications (4-33\%), endoscopic PEG is currently the most 
widely used method for long-term ileus tube insertion and maintenance; however, the mortality and morbidity rates associated with this procedure are $1-2 \%$ and $3-12 \%$, respectively ${ }^{16)}$. Herein, we achieved safe and easy placement of an ileus tube via gastrostomy using a commercially available gastrostomy kit. The greatest advantage of this procedure lies in the sheathed PS needle from the percutaneous gastrostomy catheter kit and the 16-F ileus tube having approximately the same diameter, which makes it easy to gradually feed the ileus tube into the stomach while the sheath is peeled away, despite some resistance as the ileus tube is inserted into the sheath. We believe that this gastrostomy procedure will be an effective way to treat patients with refractory intestinal obstruction.

In conclusion, five patients suffering from refractory intestinal obstruction had their nasogastric tube replaced with an ileus tube by gastrostomy using a percutaneous gastrostomy catheter kit. This method was safe and easy to perform, with no complications and a markedly improved patient QOL.

\section{Conflict of interest disclosure}

The authors have declared no conflict of interest.

\section{References}

1) Midorikawa $Y$, Yamamoto $T$, Karube $Y$, et al. Home care of patients with advanced terminal cancer who had improved QOL after undergoing gastrostomy for gastrointestinal obstruction caused by peritonitis carcinomatosa. Jpn J Cancer Chemother. 2000;27:745-747. (in Japanese).

2) Sekino T, Sugimoto T, Mikamo H, et al. Ileus due to right-sided colon cancer in two bedridden old patients. $J$ Jpn Coll Surg. 2003;28:1029-1033. (in Japanese).

3) Naruo H, Morise M, Kuroyama S, et al. Decompression PEG for peritonitis carcinomatosa. Surg Ther. 2004;90:928932. (in Japanese).

4) Nakagawa T, Takahashi A, Yamanaka A, et al. Percutaneous endoscopic gastrostomy to decompression for ileus of terminal stage of gynecological cancer. Adv Obstet Gynecol. 2009;61:234-235. (in Japanese).

5) Maetani I, Shigoka H, Ukita T, et al. The palliative role of PEG for pancreatico-biliary malignancies. $J$ Biliary Tract Pancreas. 2010;31:75-80. (in Japanese).

6) Nakahira S, Sugimoto K, Okamura S, et al. The palliative role of percutaneous endoscopic gastrostomy with jejunal extension (PEG-J) in an advanced pancreatic cancer patient with duodenal stenosis- a case report . Jpn J Cancer Chemother. 2007;34:2007-2009. (in Japanese).

7) Kawasaki N, Suzuki Y, Onuma M, et al. Percutaneous endoscopic gastrostomy-jejunostomy for nutritional management and percutaneous endoscopic gastrostomy for decompression, a case report. J Jpn Soc Parenter Enteral Nutr. 2008;23:273-276. (in Japanese).

8) Silk DBA, Bray MJ, Keele, AM, et al. Clinical evaluation of a newly designed nasogastric enteral feeding tube. Clin Nutr. 1996;15:285-290.

9) Gauderer MWL, Ponsky JL, lzant RJ Jr, et al. Gastrostomy without laparotomy : a percutaneous endoscopic technique. J Pediatr Surg. 1980;15:872-875.

10) Park RH, Allison MC, Lang J, et al. Randomised comparison of percutaneous endoscopic gastrostomy and nasogastric tube feeding in patients with persisting neurological dysphagia. BMJ. 1992;304:1406-1409.

11) Miller RE, Castlemain B, Lacqua FJ, et al. Percutaneous endoscopic gastrostomy. Results in 316 patients and 
review of literature. Surg Endosc. 1989;3:186-190.

12) Tokumo H. Procedures similar to PEG (percutaneous endoscopic jejunostomy and percutaneous trans-esophageal gastro-tubing). Mod Phys. 2003;23:439-443. (in Japanese).

13) Shinoda M, Kojima M, Fukase $\mathrm{T}$, et al. Percutaneous transgastric intesinal decompression: the management of malignant bowel obstruction without nasal intubation. Surg Today. 1994;24:937-939.

14) Nakamura T, Ikehata Y. Experience of pergastrostomal intensional decompression for carcinomatous ileus. Jpn $J$ Chemother. 2000;27:741-744. (in Japanese).

15) Hasebe $\mathrm{T}$, Ueda $\mathrm{T}$, Wakabayashi $\mathrm{M}$, et al. Experience with intestinal decompression using pergastrostomal route for peritonitis carcinomatosa. J Clin Surg. 2002;57:1283-1286. (in Japanese).

16) Chen HL, Shih SC, Bair MJ, et al. Percutaneous endoscopic gastrostomy in the enteral feeding of the elderly. Int J Gerontol. 2011;5:135-138.

[Received November 2, 2015 : Accepted December 9, 2015] 